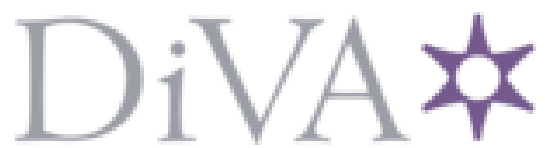

http://www.diva-portal.org

This is the published version of a paper presented at Second International Scientific-

Practical Conference Problems of Infocommunications Science and Technology (PIC S\&T).

Citation for the original published paper:

Kuzminykh, I., Kabali, S. (2015)

Development of smart infocommunication networks for intellectual municipal services

In: IEEE (ed.), Second International Scientific-Practical Conference Problems of

Infocommunications Science and Technology (PIC S\&T), 13-15 Oct. 2015, Kharkiv,

Ukraine Kharkiv, Ukraine: IEEE

https://doi.org/10.1109/INFOCOMMST.2015.7357291

N.B. When citing this work, cite the original published paper.

Permanent link to this version:

http://urn.kb.se/resolve?urn=urn:nbn:se:bth-15952 


\title{
Development of Smart Infocommunication Networks for Intellectual Municipal Services
}

\author{
Ievgeniia Kuzminykh, Stephen Kabali \\ Telecommunication System Department \\ Kharkov National University of Radio Electronics \\ Kharkov, Ukraine \\ domoveno@yahoo.com, kabalistephen@yahoo.com
}

\begin{abstract}
This paper represents the smart system that bypasses the normal functioning algorithm of traffic lights, triggers a green light when the lights are red or to reset the timer of the traffic lights when they are about to turn red. Different pieces of hardware like microcontroller units, transceivers, resistors, diode, LEDs, digital compass and accelerometer will be coupled together and programmed to create a unified complex intelligent system.
\end{abstract}

Keywords-smart city; style; smart mobility; microcontroller; traffic light

\section{INTRODUCTION}

A smart city (also smarter city) uses digital technologies or information and communication technologies (ICT) to enhance quality and performance of urban services, to reduce costs and resource consumption, and to engage more effectively and actively with its citizens. Sectors that have been developing smart city technology include government services, transport and traffic management, energy, health care, water and waste. Smart city applications are developed with the goal of improving the management of urban flows and allowing for real time responses to challenges [1].

A smart city is built upon the following elements:

- Smart Mobility;

- Smart Living;

- Smart People;

- Smart Government;

- Smart Economy;

- Smart Environment.

In this paper we shall mainly be looking at some elements of Smart Living and Smart Mobility.

\section{SMART MOBILITY TOPOLOGY}

Mobility describes the ability of people and goods to move around an area, and in doing so to access the essential facilities, communities and other destinations that are required to support a decent quality of life and a buoyant economy. Mobility incorporates the transport infrastructure and services that facilitate these interactions.

Urban Mobility will be one of the toughest challenges for cities around the globe. In many cities, existing mobility systems are already inadequate, yet urbanization and increasing populations will increase demand still further. Cities have traditionally sought to solve such challenges by adding new capacity to match demand. However, a capacity-building approach alone is neither efficient nor sustainable. On top of the growing demand, mobility needs are changing and evolving, and travelers' expectations of seamless movement are becoming ever greater. Many new mobility solutions are emerging, which leverage technology to improve service provision and manage demand. A holistic response to urban mobility optimizes both supply and demand solutions to facilitate more sustainable outcomes.

For better understanding realization of the above system and the experiment bit of this paper, we shall break the mobility sector into layers [2].

The 5 mobility layers are [3]:

1) User Experience Layer, this is the layer whereby the user receives shipping, information, or other services from the transportation company, and where transportation actually occurs.

2) Transportation Services Layer, this is the layer whereby transportation companies provide services to users.

3) Information Collection Layer, at this layer the information is gathered regarding how the services provided by transportation companies are used by users.

4) Information Management and Control Layer, at this point the information is managed and controlled in order to ensure that transportation companies smoothly provide the services in the transportation services layer.

5) Transportation Company Coordination Layer, this is the point whereby each transportation company's information is gathered, analyzed, and provided, in order to optimize transportation inside the entire city, thereby guiding the operation and control of the transportation companies.

We shall be working within layer 4 of the smart mobility structure.

The main result should be to setup both hard and software which will be aimed at helping control traffic lights for high Priority vehicle like ambulances, fire brigades, military and police cars, government and presidential convoys etc. at roundabouts and junctions to grant them a swift passage which could help them reach 
their destinations in the needed period of time and reduce the siren noise around the cities.

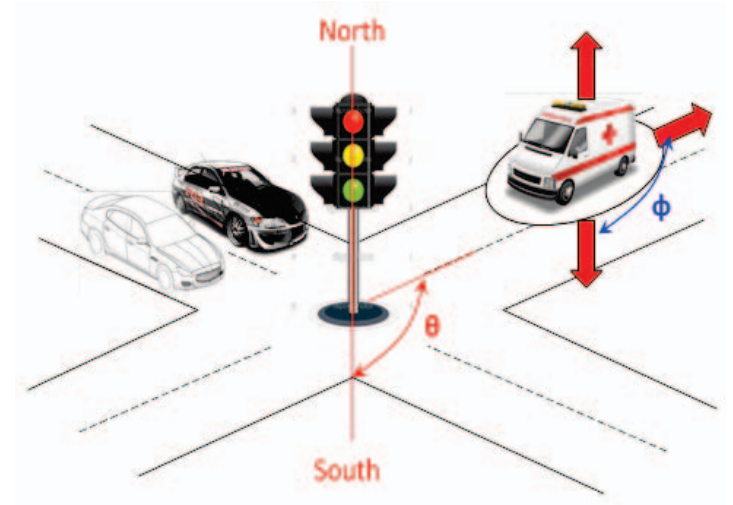

Fig. 1. Topology of developed system.

\section{PROJECT DEVELOPMENT}

\section{A. Topology of project}

The operating principle of the system is as follows. As a vehicle carrying this intelligent system (ambulance, fire brigade, police and other emergency vehicles) approach a given distance at a certain junction/roundabout, the traffic lights are automatically switched to green in order to allow movement without stopping at the junction. High priority vehicles are always in a rush to get to their give location in order to get work done without stopping at traffic lights. 45 or $30 \mathrm{sec}$ can mean a lot to save a life and an ambulance can't wait 30 seconds while it tries to maneuver through heavy traffic.

The required direction of movement is automatically calculated using special equipment. The car is installed with a microprocessor system with an electronic compass with an accelerometer and a transmitter of a limited range $(50 \ldots 100 \mathrm{~m})$. At the traffic lights is also a management system with a transceiver radio module that processes the information from moving objects. Topology of developed system is shown on fig. 1 .

The traffic lights work with a known orientation, and the orientation and direction of movement of the vehicle are calculated by the on-Board microprocessor system. This information is transmitted to the traffic lights constantly. Once the car is approaching the traffic light in the range of the transceivers, the information is being transferred and the traffic lights initialize the algorithm to switch to the desired direction.

\section{B. Hardware development}

Figure 2 shows a block diagram of a microprocessor unit and how different units are connected to it in order to achieve a smart system that overrides the normal function algorithm of traffic lights to grant any high priority transport clear passage on busy road Junctions or roundabouts.

The setup consists of the following units:

- $\mathrm{MC}$ - microcontroller;

- Power supply;
- Voltage regulator;

- Debug port;

- Digital compass/ magnetometer;

- Transceiver;

- Traffic light.

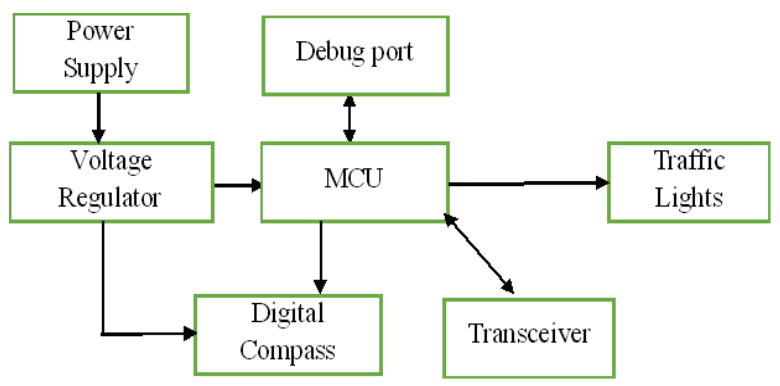

Fig. 2. Block diagram for setup.

The Microcontroller Unit (MCU) is used to control the entire device and coordinate between the different other components of the system. In this project, we used stm32f050f4p6 microcontroller [4].

This MCU is an Arm 32- bit Cortex- M0 CPU with an operating frequency of up to $48 \mathrm{MHz}$.

The tests were done using Nordic semiconductor's nRF24L01 [5] wireless transceiver with $2.4 \mathrm{GHz}$ ISM band operation and up to $2 \mathrm{Mbps}$ on air data rate. This transceiver unit was chosen due to its low cost of production, easy programing, and compatibility to the system, low operating temperature, size and power efficiency.

Knowing the direction from which the signal is being generated is very important in this project. Since we are dealing with traffic and traffic lights, it would be dangerous or even catastrophic if all traffic lights were triggered to turn green, so the direction the transmission is coming in from is very important and no better way to register it than using a digital compass/ magnetometer.

For this test, we used the HMC5883L magnetometer.

HMC5883L [6] has the following benefits that made it the best choice for the project:

- Small Size for Highly Integrated Products. Just Add a Microcontroller Interface, Plus Two External SMT Capacitors Designed for High Volume, Cost Sensitive OEM Designs Easy to Assemble \& Compatible with High Speed SMT Assembly;

- Enables $1^{\circ}$ to $2^{\circ}$ Degree Compass Heading Accuracy;

- Enables Low-Cost Functionality Test after Assembly in Production;

- Compatible for Battery Powered Applications.

After assembling all components device is ready for programming (fig.3). 


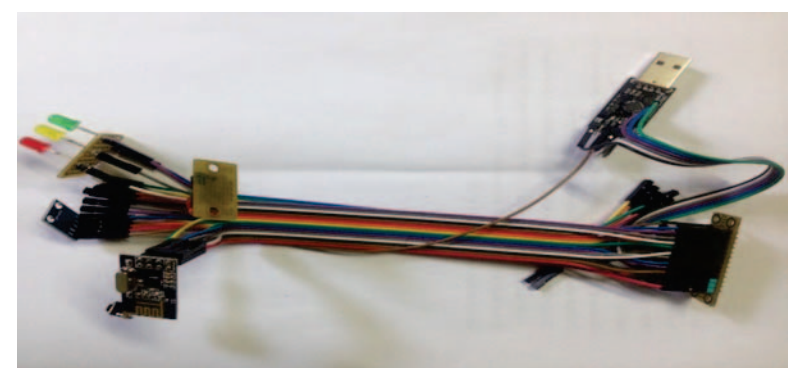

Fig. 3. Device after assembling

\section{Software development and algorithm}

Fig. 4 shows the traffic light control algorithm. Fig. 5 shows the car operation algorithm

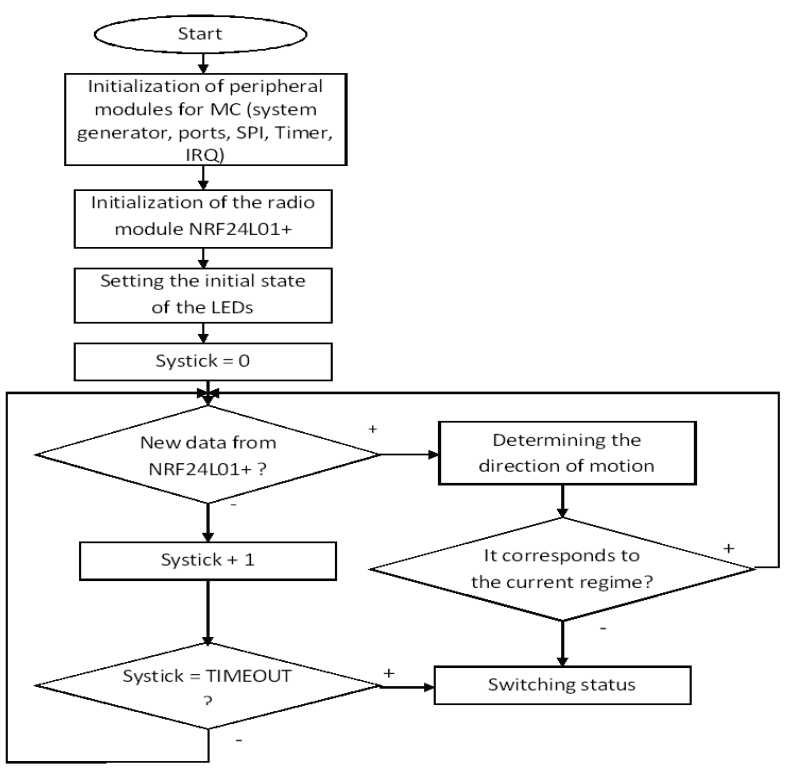

Fig. 4. Traffic light control algorithm.

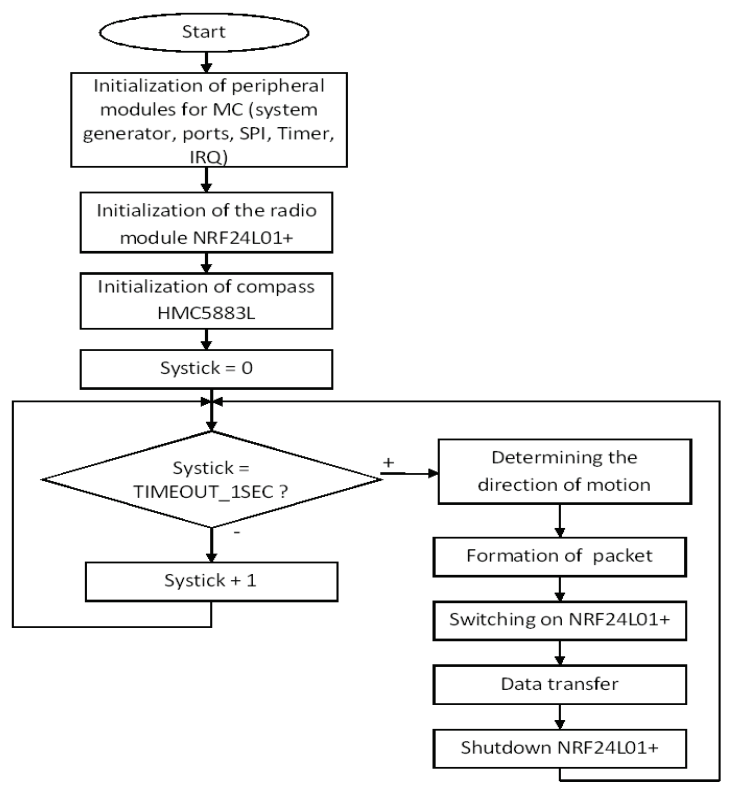

\section{CONCLUSION}

This work looks at what information and telecommunications are needed to develop and nurture a smart city. It lists five essential elements for any smart city ICT planning policy. These five essentials are closely related and build upon each other to ultimately provide a comprehensive ICT solution. This solution takes the form of a ubiquitous digital platform, which is available across the city (via Wi-Fi hotspots, private networks or local information kiosks) to all members of the smart city or community. It facilitates collaboration at a local level in a streamlined digital fashion, reducing energy and time costs for all participants and increasing quality of life within the community.

In this paper we created a system that bypasses the normal functioning algorithm of traffic lights, triggers a green light when the lights are red or to reset the timer of the traffic lights when they are about to turn red. Different pieces of hardware like microcontroller units, transceivers, resistors, diode, LEDs, digital compass and accelerometer were coupled together and programmed to create one complex intelligent system that eased movement of high priority vehicles around smart cities.

\section{REFERENCES}

[1] N. Komninos,"The architecture of intelligent cities: Integrating human, collective and artificial intelligence to enhance knowledge and innovation," The 2nd IET International Conference on Intelligent Environments,vol. 1, pp. 13-20, 2006.

[2] V. Cagri Gungor, D. Sahin, T. Kocak, S. Ergut, C. Buccella, et al., "A survey on smart grid potential applications and communication requirements," IEEE Trans. on Industrial Informatics, vol. 9, no. 1, pp. 28-42, February 2013.

[3] T. Okuda, S. Hirasawa and et. "Smart Mobility for Smart Cities", Hitachi Review, Vol. 61, No. 3, pp.141-146, 2012.

[4] "STM32F050x4 STM32F050x6". Datasheet, STMicroelectronics group of companies, 97p., 2012.

[5] "nRF24L01+.Single chip $2.4 \mathrm{GHz}$ transceiver. Preliminary Product_Specification v1.0." Nordic Semiconductor, 75p.

[6] "3-Axis Digital Compass IC HMC5883L", Honeywell's Magnetic Sensors' Advanced Information, 20 p., 2013.

Fig. 5. The algorithm of functioning of mobile systems. 